\title{
Una planta sin clásicos. La berenjena en la farmacología medieval y renacentista ${ }^{1}$
}

\author{
Miguel Ángel GonZÁLEz ManjARrÉS \\ Universidad de Valladolid \\ miguelan@fyl.uva.es
}

Recibido: 9 de diciembre de 2014

Aceptado: 18 de enero de 2015

\section{RESUMEN}

La berenjena (Solanum melongena L.) es una planta solanácea de múltiples variedades, cuyos ancestros salvajes se sitúan en Indochina y el este de África. Su cultivo fue muy temprano en zonas de China e India. Aun así, no se extendió al Occidente antiguo ni apenas se conoció, de ahí su ausencia en los textos clásicos de botánica y farmacología. Fueron los árabes quienes llevaron el cultivo de la planta por el Norte de África y Al-Andalus, de donde pasó ya a Europa. Los primeros testimonios occidentales de la berenjena aparecen en traducciones latinas de textos árabes, para incorporarse luego a la literatura farmacológica medieval y, más tarde ya, a la del Renacimiento, que empezó a tratar de ella por su posible parecido con una especie de mandrágora. Pese a que se le reconocían algunas virtudes medicinales, siempre se la tuvo bajo sospecha por ser de sabor poco agradable, indigesta y causante de algunas afecciones. Solo los botánicos de finales del Renacimiento describirían la planta y sus variedades con criterios más «científicos» y botánicos, ya sin apenas intereses farmacológicos.

Palabras clave: Berenjena. Farmacología latina. Edad Media. Renacimiento.

GonzÁLez MANJARRÉs, M.Á., «Una planta sin clásicos. La berenjena en la la farmacología medieval y renacentista», Cuad. Fil. Clás. Estud. Lat. 35.1 (2015) 119-142.

\section{A Non-Classical Plant: The Aubergine in the Medieval and Early Modern Pharmacology}

\begin{abstract}
Aubergine (Solanum melongena L.) is a plant from the Solanaceae family with multiple varieties, whose wild ancestors come from Indochina and East Africa. Although in China and India was very early cultivated, it was not extended to the ancient West, where it was hardly known; this would be the reason for its absence in the ancient botanical and pharmacological literature. It was the Arabs who expanded the growing of this plant in the North of Africa and Al-Andalus, from where it went to Europe. The first Western testimonies about the aubergine are found in Latin translations of scientific texts from Arabic, which were then incorporated into the Medieval and Renaissance pharmacological literature. In
\end{abstract}

\footnotetext{
${ }^{1}$ Este trabajo se adscribe al Proyecto «Estudios de medicina práctica en el Renacimiento» (ref. FFI201341340-P), financiado por el Ministerio de Economía y Competitividad.
} 
Renaissance, however; the plant began to be studied because of its similarities with a type of mandrake. Even though the aubergine was supposed to have some medicinal virtues, it was always suspected to be of poor taste, hard to digest and causing some diseases. Only in the Renaissance the plant and its varieties would be described by botanists from a more «scientific» and botanical perspective, with little pharmacological interest.

Keywords: Aubergine. Eggplant. Latin Farmacology. Middle Ages. Renaissance.

SumARIO: 1. Introducción. 2. La Edad Media latina. 3. El Renacimiento. 4. Conclusiones. 5. Referencias bibliográficas.

\section{INTRODUCCIÓN}

La berenjena es una planta solanácea (Solanum melongena L.) cuyo fruto constituye una importante fuente de consumo mundial, sobre todo en China, la India y el ámbito mediterráneo, sus máximos productores. La familia de las Solanaceae comprende unas 2.300 especies, y casi la mitad de ellas pertenecen al género Solanum. La mayoría de dichas especies es endémica del continente americano y aproximadamente el 20\% lo sería del «Viejo Mundo». La evolución genética de las solanáceas ha generado una gran variedad fenotípica y cualitativa en sus especies, aunque muchas de ellas se caracterizan por contener dosis más o menos elevadas de alcaloides (solanina, atropina, hiosciamina, nicotina), que las hacen tóxicas y, al tiempo, dotadas de valiosas propiedades farmacológicas. No obstante, hay solanáceas alimenticias que constituyen vegetales de altísimo consumo mundial, como son sobre todo la patata (Solanum tuberosum L.), el tomate (Solanum lycopersicum L.) y la propia berenjena ${ }^{2}$.

Parece ser que los ancestros salvajes de la berenjena proceden de la zona centrooriental de África (Khan 1979a). Uno de ellos, la variedad Solanum incanum L., se extendió al sudeste asiático y dio lugar a la berenjena común, que todavía hoy en la India puede encontrarse en forma silvestre o semisilvestre (Lester-Hasan 1991). La planta, que pertenece al subgénero Leptostemonum (caracterizado por espinas puntiagudas en la superficie), suele clasificarse a su vez en dos secciones: la primera incluye el Solanum melongena L. (berenjena común) y el Solanum macrocarpon L. (berenjena africana o gboma); la segunda, el Solanum aethiopicum L. (berenjena etíope).

La zona de Indochina es el centro del origen y diversidad de las berenjenas. Las primeras especies serían plantas altas, con hojas espinosas y frutos pequeños, verdes, redondeados y muy amargos. Pero la domesticación, la mutación, los cruces naturales, la selección humana y la hibridación provocaron una gran diversidad genética (Daunay et alii 2001; Doganlar et alii 2002; Sękara-Cebula-Kunicki 2007), manifestada sobre todo en la forma del fruto (redondeado, ovalado, alargado), su color (verde,

\footnotetext{
${ }^{2}$ La literatura científica sobre esta familia es muy amplia, aunque se recomiendan los trabajos colectivos reunidos progresivamente en Hawkes et alii (1979) y (1991), Nee et alii (1999), Berg et alii (2001).
} 
blanco, púrpura, violeta, negruzco y, cuando está maduro, marrón, rojo o amarillo) y su tamaño (longitud de 4 a $45 \mathrm{~cm}$., grosor de 2 a $35 \mathrm{~cm}$. y peso de 15 gr. a kilo y medio). De hecho, la berenjena común cuenta con 475 variedades de acuerdo a la forma de sus diversas partes, si bien se suelen diferenciar tres grandes «ramas» según el aspecto del fruto: Solanum melongena var. sculentum Dunal (Nees), de frutos redondeados, ovales, con forma de huevo; Solanum melongena var. serpentinum L., con frutos alargados y delgados; Solanum melongena var. depressum L., de frutos diminutos. En todo caso, es también común distinguir varios tipos conjuntos por la forma del fruto y su lugar principal de cultivo: berenjenas occidentales (color púrpura oscuro, ovales o alargadas); berenjenas italianas (diminutas, estrechas o redondeadas, más tiernas y de piel más fina); berenjenas orientales (color púrpura o verde violáceo, delgadas o redondeadas, que a su vez se dividen en múltiples subclases) (Daunay 2008).

El cultivo de la berenjena en las zonas de India y China remonta a tiempos muy antiguos. Al parecer, hay textos sánscritos del 300 a.C. que ya la documentan con diferentes nombres, mientras que en la literatura antigua china se recoge por primera vez en el siglo I a.C. (Khan 1979b; Wang et alii 2008). Pese a su gran variedad, en el proceso de domesticación la berenjena tendió a alargarse, a adoptar un color cada vez más oscuro y a reducir su amargor originario. La planta, en todo caso, se extendió hacia Oriente y Occidente siempre bajo unas condiciones climáticas específicas: temperatura alta, mucha luz y agua abundante, de ahí que al aire libre solo se pudiera cultivar en climas tropicales, subtropicales y templados, y nunca en climas fríos y extremos.

Pese a su antiguo cultivo y consumo en las zonas mencionadas, la literatura antigua grecolatina no da cuenta de la berenjena ni como planta de adorno ni como ingrediente culinario ni como elemento farmacéutico. Su extensión a zona occidental, por tanto, fue seguramente tardía, posclásica, y debida primero a los persas y luego ya a los árabes: a partir de ellos, en efecto, se amplió su cultivo a zona bizantina y llegó hasta el norte de África, de donde pasaría a Al-Andalus y al sur de Italia hasta incorporarse definitivamente a la literatura latina medieval (Daunay-Janick 2007; Daunay-Janick-Laterrot 2007). En el Califato oriental se documenta desde los primeros tiempos, y hay referencias médicas ya en Mesué el Viejo (Yuḥanna ibn Māsawaih, 777-857), Rhazes (Al-Rāzī, 865-925) y algo después en Avicena (Ibn Sīnā, 980-1037) o Ibn Butlān († 1068). En el Norte de África y Al-Andalus, por su parte, hay también menciones y descripciones tempranas: el judío africano Isaac Israelí (Isḥāq ibn Sulaymān al-Isrā'ili, 832-932), el médico y filósofo cordobés Averroes (Ibn Rushd, 1126-1198), el judío cordobés Maimónides (Ibn Maymūn, † 1204) o el agrónomo andalusí Ibn al- 'Awān (siglos XII-XIII) testimonian el consumo y cultivo habituales de la berenjena en dichas zonas ${ }^{3}$. Casi todos ellos, en cualquier caso, habrían de ser,

\footnotetext{
${ }^{3}$ Ibn al-'Awān describe cuatro variedades de berenjena: egipcia (fruto blanco y pétalos violetas); siria (fruto violeta y pétalos azul claro); local (fruto de color púrpura oscuro); cordobesa (fruto casi negro) (ClémentMullet 1864-1867, vol.2, cap.25). Para la berenjena en el mundo árabe y judío y sus fuentes principales, que aquí solo interesan en sus versiones latinas medievales, pueden verse Löw (1924-1934, vol.3, pp.377-379); Watson (1983, pp.70-73); Lev-Amar (2008, pp.401-402).
} 
una vez se fueron traduciendo al latín, las fuentes en que se basaran los textos farmacológicos y médicos de la Edad Media occidental, como se dirá más adelante.

Si la berenjena, por tanto, se cultivó y consumió de forma cada vez más amplia, las fuentes médicas y farmacológicas árabes y luego latinas casi siempre sospecharon de ella - posiblemente por su amargor (producto de su contenido en saponina, solasonina y solamargina) y su parecido con otras solanáceas como la belladona o la mandrágora-, con lo que desaconsejaban su uso y, a lo sumo, advertían de las precauciones necesarias con que debía ingerirse. Aun así, a veces también se le reconocieron algunas cualidades medicinales, pero siempre con parca recomendación, y ello frente a los efectos salutíferos que hoy día se le atribuyen: actividad antioxidante, acción contra lípidos y colesterol y, en especial, efectos inhibitorios sobre determinados tumores cancerígenos (Das et alii 2011; Milner et alii 2011).

Si los tratados latinos medievales suelen aportar escasas novedades a los datos árabes, en el Renacimiento ocurre algo parecido, aunque se vaya precisando su descripción botánica y se vuelvan más realistas sus representaciones pictóricas. En las páginas que siguen se dará cuenta de todo ello: tras un recorrido pormenorizado por las principales fuentes medievales que se ocupan de la berenjena -tanto las versiones latinas de obras árabes como los trabajos originales de diferentes autores-, se pasará a analizar su tratamiento, descripción e identificación en algunos de los textos más relevantes del Renacimiento (comentarios a Dioscórides y herbarios propios). Aunque el objetivo del estudio son los textos, se tendrá también en cuenta la tradición de las ilustraciones ${ }^{4}$, que puede ofrecer datos interesantes sobre el conocimiento real de la planta o, en no poco casos, sobre la continuidad de una transmisión más bien libresca.

\section{LA EDAD MEDIA LATINA}

Pese al temprano cultivo de las berenjenas en el Califato occidental, parece que en la Europa de la Edad Media la planta tardó algo más en introducirse como elemento botánico, culinario y farmacológico. El primer testimonio latino, no obstante, es temprano: una traducción que en la segunda mitad del siglo XI hizo en Monte Cassino el monje Constantino Africano (Burnett-Jacquart [eds.] 1994) de una obra dietética, el Dietarum particularum liber, del judío Isaac Israelí, que nació en Egipto y murió en Túnez en 932. El término latino que empleó Constantino para las berenjenas fue melongiana, con el que recogería el árabe (al-)bādinjānah, a su vez procedente del persa bātingān, que era copia de un sánscrito bhandițâki . El nombre añade ya una primera parte que parece de influencia griega: bien el término $\mu \tilde{\eta} \lambda o v$ (aludiría a la forma de manzana del fruto) o bien el prefijo $\mu \varepsilon \lambda \alpha v$ - (aludiría al color negro del

\footnotetext{
${ }^{4}$ Como ha señalado Givens (2006, p.115), los textos farmacológicos a menudo estaban guiados «by a combination of verbal and visual strategies», aun cuando no se sabe aún con certeza si, en los casos más destacados, su finalidad era práctica o puramente decorativa. Sobre las ilustraciones en los herbarios y su utilidad para el reconocimiento de plantas, pueden verse también Collins (2000) y Swan (2006).
} 
fruto). En tal sentido, la denominación en griego bizantino fue $\mu \varepsilon \lambda \imath \tau \zeta \alpha ́ v \alpha$, que a su vez explicaría la forma itálica «melanzana», y que es posible estuviera ya extendida en el sur de Italia en época del monje Constantino e influyese en su propuesta latina ${ }^{5}$.

El texto de Isaac clasifica la planta, según el sistema de gradación galénica, como cálida y seca en grado segundo, causa de su calidad agria y amarga, que daña la lengua y que puede generar con facilidad humores coléricos. El fruto, como solanácea, puede provocar daños, sobre todo en la piel: manchas, erupciones, ulceraciones, lepra y apostemas. Recomienda una preparación especial para menguar sus perjuicios: se corta, se sala, se mete en agua caliente, se lava varias veces, se seca y se cuece con carne de vaca, oveja o cerdo. Si se quiere comer sin carne, recomienda que se cueza con vinagre, aceite onfacino o salmuera:

Melongiana calida et sicca est in fine secundi gradi, quod testificatur eius acumen et amaritudo et morsus quo lingua inficitur, idcirco convertibilis in cholericam naturam. Hec est eius proprietas, unde cutem corporis corrumpit, lentigines et impetigines, cancrum, elephantiasiam durumque ad dissolvendum apostema generat et similia facit. Que ut minoris fiat nocumentum, temperetur et findatur et sale impleatur, deinde diu post in aqua calida dimittatur, postea in aliam mittatur, et bis aut ter lavetur, ut aqua qua lavatur careat omni nigredine, deinde elixetur, et aqua eiecta cum pingui carne boum seu pecudum porcorumque et similium recoquatur. Illam autem absque carne comedere volentes coquant cum aceto, oleo omphacino et obsomogaro et similibus (Isaac Israelí $1515, \mathrm{f}, 128 \mathrm{va})^{6}$.

Así pues, Isaac Israelí se hace eco de una tradición que valora negativamente los efectos de la berenjena, pero cuya ingesta sería habitual en el Norte de África como alimento individual o guarnición de carnes. En todo caso, no se le reconocen beneficios farmacéuticos. El texto latino de Isaac habría de tener una fortuna interesante, pues a él remiten luego algunas obras médicas de ámbito itálico en una repetición de cualidades meramente libresca, que nada asegura respecto al cultivo y conocimiento real de la planta en esta zona. En Salerno, por ejemplo, se incorpora solo a finales del siglo XII a la versión ampliada del Circa instans (Holler 1941, p.66), sin que otros textos farmacológicos relevantes de dicha «Escuela» traigan una descripción propia de la planta.

\footnotetext{
${ }^{5}$ Aunque no es aquí lugar para un estudio pormenorizado de la terminología, cabe decir que otros nombres modernos proceden en cambio de la transcripción directa del árabe (Corriente 2008, p.60), bien sin artículo: español «berenjena», portugués «beringela»; bien con artículo: catalán «alberginia», que luego pasó al francés «aubergine». Es esta la forma que adoptaron los ingleses para llamar a la planta, aunque a finales del siglo XVI forjaron el nombre «eggplant», por el parecido con un huevo que tenían los frutos de algunas variedades de la India. «Eggplant», de hecho, es la forma común del inglés americano, mientras que en el inglés asiático, por influencia portuguesa, se la denomina «brinjal» (Dubler 1942; Arveiller 1969; Mállo Salgado 1993³ p.303).

${ }^{6}$ La edición de Isaac aquí citada presenta glosas de Pedro Hispano (†1277), que para la berenjena añade una acotación sobre sus cualidades teniendo más bien presente el texto de Avicena: como es cálida y seca, en efecto, genera humor colérico, inflama el estómago y puede allí calentarse hasta transformarse en melancolía o cólera adusta. Y matiza otra cuestión: si como alimento se comen berenjenas en gran cantidad, crean opilaciones, pero como fármaco, y en escasa cantidad, las eliminan.
} 
En la segunda mitad del siglo XII, en Toledo, traduce al latín Gerardo de Cremona el célebre Canon de Avicena (Jacquart-Micheau 1990, 147-160; Resman 2002), que incluye una descripción cualitativa de la berenjena, pero sin ofrecer tampoco datos morfológicos, pues afirma que es una planta bien conocida (para el contexto, obviamente, de la zona persa de comienzos del siglo XI). Al parecer, Juan Mesué la había clasificado como una planta fría, pero Avicena la consideraba -igual que Isaaccálida y seca en segundo grado. Solo se ingiere el fruto y resulta siempre bastante perjudicial: genera bilis negra y opilaciones (sobre todo de hígado y bazo), da mal color, provoca afecciones epidérmicas y hemorroides y causa tristeza. Avicena, no obstante, le reconoce ya dos beneficios: si se cuece en vinagre, puede resolver las mismas opilaciones hepáticas y, si se hace una epítema con las cabezas del fruto secas y aplastadas, sana precisamente las hemorroides. La planta, por lo demás, puede ser laxante si se cuece en aceite $o$ astringente, si se hace en vinagre:

Melongena quid est. Nota est. Electio. Que ex ea est antiqua est mala, et eius natura est sicut frixi eius; recens vero est sanior. Natura. Secundum filium Mesaugue est frigida, verumtamen verum est quod virtus in ipsa dominans est caliditas et siccitas in secundo propter amaritudinem et acuitatem ipsius. Operationes et proprietates. Generat melancholiam et generat opilationes. Decoratio. Corrumpit colorem et denigrat superficiem corporis et citrinat colorem. Que ex melongenis sint parve comeduntur excorticate, et ipse quidem faciunt possidere pannum. Apostemata et bothor. Generat cancros et duritiem et lepram. Membra capitis. Generat sodam et facit multiplicare tristitiam. Membra nutrimenti. Generat opilationes epatis et splenis, nisi illa que cocta est in aceto: ipsa enim aperit opilationes epatis fortasse. Membra expulsionis. Generat emorroydas, verumtamen si ex capitibus eius in umbra siccis et contritis fiat epithyma, confert emorroydibus. Et melongena quidem non habet proportionem ad stringendum aut solvendum, verumtamen cum coquitur in oleo, solvit, et in aceto, stringit (Avicena 1507, f. 132va).

Si Gerardo de Cremona emplea el término melongena ${ }^{7}$, la versión latina anónima que en el último tercio del siglo XIII se hizo de la principal obra médica de Averroes (Mazliak 2004) -conocida por el latino Colliget- llama a la berenjena melongia. Y en este caso señala el cordobés que el cultivo de la planta y el consumo de su fruto eran muy corrientes en su tierra (estamos en el siglo XII), sobre todo tras desaguarlas y cocerlas con carnes, como ya señalara Isaac. Asegura, pues, que es un alimento agradable, cuyo perjuicio (sequedad y estipticidad) se elimina de la manera indicada y que incluso, pese a que se diga que puede engendrar melancolía, tiene alguna virtud medicinal, que aquí no obstante se omite:

Melongiae sunt ex his ex quibus nos facimus in terra nostra multa cibaria delicata et, postquam proiecta est prima aqua suarum decoctionum et coquuntur cum carnibus pin-

${ }^{7}$ El filósofo y naturalista alemán Alberto Magno († 1280) habría de variar el nombre en melangena, que solo cita para destacar su triple sabor: sic inveniuntur tres sapores in melangena, amarus, acutus et stypticus (Meyer 1867, p.204). 
guibus, sunt multum delectabiles. Et ego reputo ipsum temperatum cibum, postquam sic factum est, propterea quia pars acuta quae est in eo removetur per primam decoctionem, et sua siccitas et stypticitas removentur propter carnes decoctas in eo. Et quamvis medici dicant quod generant humorem melancholicum similem humori generato ex caulibus, tamen consyderare debemus in cibis duas res: una est res quae secum miscetur, quae potest removere malitiam, si est, et delectatio cibi, haec est secunda; et quando est multum delectabilis, laesio quae provenit ex eo non est multum manifesta, et hic est unus ex delectabilibus cibis. Isti sunt cibi manifesti apud nos, in quibus est virtus aliqua medicinalis (Averroes 1553, f.50rb).

Por la misma época en que se traduce el Colliget se pone también en latín un texto de medicina terapéutica titulado Tacuinum sanitatis, cuyo autor fue el médico y filósofo nestoriano del siglo XI Ibn Butlān (Elkhadem 1990). El texto, estructurado en una serie de tablas que sintetizan las cualidades y virtudes de los diferentes medicamentos y otros elementos que inciden en la salud, incluye también la berenjena (que como Constantino nombra melongiana), sin añadir apenas nada nuevo a lo ya dicho en fuentes previas. Se destaca otra vez la diferencia entre las añejas (cálidas y secas y, por tanto, amargas) y las tiernas (frías y secas y, por tanto, dulces), así como entre las crudas (indigestas) y las guisadas, que pueden incluso confortar el estómago si se tienen un tiempo en agua y sal y se cuecen luego con vinagre y carne. El peor modo en que pueden comerse -añade- es asadas ${ }^{8}$. Junto a tales explicaciones viene la tabla sinóptica propia del texto (figura 1), en la que se añaden algunos beneficios medicinales (hemorroides, hemorragias, vómitos, estómago), se dice que genera melancolía, que es fría, otoñal y correspondiente a la vejez.

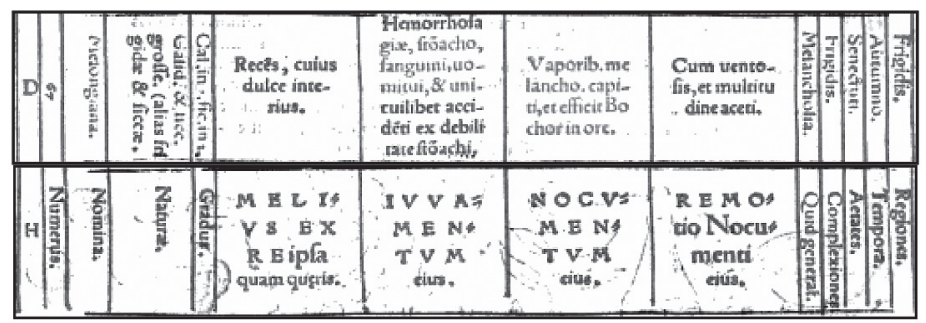

Figura 1. Tacuinum sanitatis, Estrasburgo 1531, p.56

De entonces son también algunos glosarios médicos que trataban de aclarar la abundante terminología grecolatina y, sobre todo, árabe que había entrado en la literatura médica de la época. El llamado Alphita, por ejemplo, cuya compilación se sitúa

\footnotetext{
${ }^{8}$ Melongianae. Diversantur in complexione, propter vetustatem et recentiam, dulcedinem et amaritudinem. Nam veteres amarae, calidae sunt et siccae, facientes bothor oris. Et recentes dulces, frigidae et siccae sunt. Quae crudae existentes sunt difficiles ad digerendum, et coctae econtrario. Sed temperatae cum aceto et carne, addunt in appetitu ciborum, quia confortant orificium stomachi. Verum elixari debent antequam praeparantur cum aqua et sale, et sunt cibi assueti, nec earum nocumentum adparet velociter, et peiori modo quo comeduntur sunt assatae (Ibn Butlān 1531, p.57).
} 
en la segunda mitad del siglo XIII, recoge la berenjena para dar una sintética descripción morfológica del fruto, sin añadir los datos habituales de las fuentes árabes: Melongena fructus sunt oblongi et rotundi inter ruborem et nigredinem medii (García González 2007, p.249). El texto, de ambiente salernitano, podría estar reflejando ya la variedad de berenjena más común en el sur de Italia (frutos entre alargados y redondos, de color púrpura oscuro), aun cuando quepa pensar una vez más en una mera referencia libresca.

A comienzos del siglo XIV se compone en la Italia del sur posiblemente el glosario médico de mayor influjo y difusión de la baja Edad Media: las Pandectae medicinae de Matteo Silvatico (1285-1342) (Bottiglieri 2007). Si su antecedente inmediato (la Clavis sanationis [ca. 1296] de Simón de Génova) no incluye las berenjenas, en las Pandectae se les reserva una breve entrada para ofrecer los nombres por los que se las conocía, la misma descripción del Alphita y sus cualidades según Avicena y Maimónides:

Melongena Arabice, Grece melongia vel melongea, Latine melongiana. Serapio Liber aggregatus capite melongia: fructus sunt oblongi medii intra rubedinem et nigredinem et inveniuntur ex eis citrine et albe ${ }^{9}$; et idem auctor filii Mesague: est calida et sicca in ii, generat melancoliam et opilationes epatis et splenis et generat sodam et emorroydas, verum si ex capitibus eius in umbra siccatis et contritis fiat epithima, convenit emorroydibus, et cum ipsa in oleo coquitur, solvit, sed in aceto stringit, et ideo non habet proportionem ad stringendum vel solvendum. Rabi Moyses: valet contra nauseam et vomitum et ex cibis est peior ${ }^{10}$. Avicenna ii Canonis capite 458: melongena calida et sicca, generat cancros et emorroydas (Matteo Silvatico 1541, f.130ra-b, s.v. Melongena).

También a finales del siglo XIII o comienzos del XIV se situaría el compendio farmacológico conocido por Tractatus de herbis y transmitido en su primera redacción en el manuscrito Egerton 747 de la British Library. El texto, de ambiente salernitano, se funda en el Circa instans, pero lo amplía con otras fuentes antiguas, medievales y árabes y, lo que es más importante, inaugura toda una sucesión de códices iluminados que traen dibujos de plantas a menudo precisos, naturales e innovadores. El códice incluye, en efecto, una primera y breve entrada para la berenjena, a la que se añade al margen y en letra distinta todo el texto latino de Isaac. En la descripción primera (De mellongiano) ofrece ya algunos datos botánicos interesantes: se planta en los huertos, se parece al solano llamado alquequenje, su fruto es semejante a una pera grande, de

\footnotetext{
${ }^{9}$ Matteo Silvatico remite para esta breve descripción -coincidente con la del Alphita-al Liber aggregatus de Pseudo Serapión (en realidad, traducción latina del siglo XIII de la obra farmacológica de Ibn Wāfid [ $\dagger$ ca. 1068]), pero la berenjena no se encuentra en el texto. Así advirtieron ya del error Paglia y Civitavecchia (1543, p.314), de quienes luego hablaremos: Nec obstat quod capite 541 Pandectarii, quod est de melongenis, loquatur de ipsis authoritate Serapionis, quia vel ipsius Pandectarii vel librariorum incuria factum sit, videmus ibi inesse errorem, quoniam quasi totum illud capitulum est extractum ex Avicenna et non ex Serapione, ut legentem non latet. Neque in toto Serapionis libro reperitur tale aut aliud alteriusmodi capitulum de melongenis, dummodo non sit ista tertia mandragorae species.

${ }^{10}$ La cita del médico judío puede verse en Rosner-Muntner (1970, 20,81 y 21,75).
} 
color rojizo y sabor muy amargo. Y aunque las berenjenas competen más a dietética que a medicina, la tradición previa desestima su uso por considerarlas tóxicas:

Mellongiano sive petrongiano herba est. In hortis oritur, qui similetur alchechengi, cuius frutex est magnus ut pira maior, et habet colorem subrufum, saporem amarissimum. Magis competit esui quam medicinis, sed numquam laudaverunt philosophi nec auctores, quia venenosi sunt (Ventura 2010, p.593) ${ }^{11}$.

El manuscrito incluye además la primera ilustración de las berenjenas que se conozca en el Occidente latino: hojas muy grandes y frutos piriformes, pequeños y de color blanquecino (y no rojizos, como dice el texto). El Tractatus de herbis habría de recibir más tarde nuevas reelaboraciones en latín con algunos códices que incorporan un texto semejante e ilustraciones más naturales y de mejor factura: así ocurre, por ejemplo, con el llamado códice de Manfredo de Monte Imperiale (BNP, ms. Lat. 6823), de ca. 1330-1340, que amplía la compilación del Egerton y que, para las berenjenas, ofrece una ilustración semejante, pero con los frutos más redondeados y grandes y de color violeta. La tradición continuaría en otros muchos códices a lo largo de los siglos XIV y XV, tanto latinos como en traducción francesa ( $\mathrm{Li}$ vre des simples médecines) y con el texto acostumbrado o incluso sin él y solo con imágenes, como ocurrió por ejemplo con el lujoso Vat. Chigi F. VII 158 (ca. 1400). Este códice ofrece dos dibujos para las berenjenas (blancas y rojizas: Melongianum album y Melongianum rubeum) y en ambos casos se remite a los diferentes solanos de Dioscórides (Diosc.4.70-73), aunque la segunda planta se identifica directamente con el solano furioso o belladona (Diosc.4.73); además, una mano distinta añade la siguiente anotación en referencia a la mala calidad del fruto: Nomine vulgari vocantur "petronciani», et ideo dicitur: "Petronciani nolli mangiare che non sono sani» (González Manjarrés-Herrero Ingelmo 2004, pp.331-332)12.

De forma paralela y coetánea a los códices del Tractatus de herbis se confeccionó en Lombardía, a finales del siglo XIV, una serie de manuscritos ricamente ilustrados que incorporaron el texto, generalmente abreviado, del Tacuinum sanitatis (Hoeniger 2007). En ellos se introduce también la berenjena como una planta alta con frutos piriformes y rojizos o negruzcos, a veces con figuras humanas que parecen escenificar una situación amorosa; en otras ocasiones, y en testimonios más tardíos, la berenjena se representa con forma de árbol ${ }^{13}$.

\footnotetext{
11 Obsérvese que el texto añade un sinónimo italiano para la planta («petronciano» o también «petonciano», deformación de nuevo del árabe bādinjānah). Es reseñable, por lo demás, el parecido que aquí se destaca con una especie de solano, lo que aumentaría la desconfianza hacia la planta y su consideración tóxica. Según veremos, en el Renacimiento se llegaría a asimilar con la mandrágora y otros solanos diversos.

${ }^{12}$ El códice sigue muy de cerca al llamado Masson 116 (Biblioteca de la Escuela de Bellas Artes de París), que trae la berenjena en f.277r. Una visión global sobre toda esta tradición ilustrada puede verse en Collins (2000, pp.239-298) y Givens (2006).

13 Sugieren Paris-Daunay-Janick (2009, pp.1198-1199) que las escenas amorosas podrían deberse a la supuesta condición afrodisiaca que, al parecer, se le atribuyó a la planta en la Edad Media. Como en el caso del Tractatus de herbis, hay ediciones facsímiles con importantes estudios de algunos de estos códices iluminados
} 
Así pues, en la Edad Media latina los datos que circulan sobre la berenjena son los procedentes de las traducciones latinas de fuentes árabes que se hicieron desde el siglo XI al siglo XIII y, en especial, Isaac Israelí, Avicena, Ibn Butlān y Averroes. Se sabe que el fruto se cultivaba y consumía en el Norte de África y España desde muy temprano, y probablemente también en el sur de Italia, pero los textos farmacológicos latinos apenas aportan novedades y casi ninguno presenta una descripción botánica completa. En todo caso, y a tenor de los propios tratados árabes, la berenjena suele suscitar desconfianza: se destacan sus malas cualidades (colérica y melancólica, indigesta, opilativa, dañina de la piel, etc.), pero a la vez se recomienda una serie de preparados que la vuelven digestiva y buena, entre otras cosas, para el estómago y las hemorroides, o se la tiene sin más por alimento excelente. Algunas de las ilustraciones que presentan las tradiciones del Tractatus de herbis y el Tacuinum sanitatis ofrecen dibujos bastante verosímiles y naturales de las berenjenas, lo que revelaría un conocimiento directo y, por tanto, una probable extensión de su cultivo ya por toda Italia.

\section{EL RENACIMIENTO}

El primer texto farmacológico del Renacimiento que incorpora la berenjena es

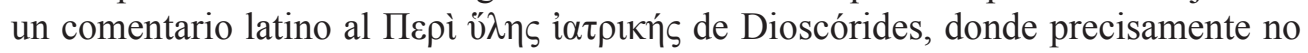
se documentaba esta planta. Se trata de uno de los Corollarii que el humanista veneciano Ermolao Barbaro (1454-1493) añadió en 1489 a su propia traducción latina del botánico griego, aun cuando ambos trabajos solo se editaron póstumos en Venecia en 1516. Pese a que pertenece aún a la primera generación de naturalistas del Renacimiento que, como Leoniceno y otros, se preocupaban sobre todo de cuestiones filológicas, los comentarios de Barbaro a Dioscórides incluyen reflexiones, críticas y anotaciones ya de calado más estrictamente botánico (Ogilvie 2006, pp.122-126). Y en el caso de la berenjena, además, habría de ser pionero en una asociación botánica que traería luego una discusión duradera: al comentar la enigmática tercera mandrágora de Dioscórides -llamada $\mu \omega ́$ pıov («enloquecedora»), pero cuyos frutos se conocieron también en la tradición interpolada por mala terrestria o mala canina-, Barbaro se acuerda por analogía de la «melanzana», nombre itálico que erróneamente considera procedería de la expresión latina mala insana, una suerte de sinónimo apropiado para un fruto tradicionalmente tenido por indigesto y de mala calidad ${ }^{14}$. La relación, por

del Tacuinum, pero una visión de conjunto puede obtenerse en Cogliati Arano (2002) o Segre Rutz (2002, pp.123-170), quien edita la llamada Historia plantarum (aunque el códice parece seguir la misma tradición, incluye el texto de Isaac, como hacía el Tractatus de herbis).

${ }^{14}$ Luego se consideró, siguiendo la interpretación errónea de los nombres, que la expresión malum insanum se debería a una supuesta actividad enloquecedora de la berenjena, análoga a la que Dioscórides asignaba al $\mu \omega ́ p ı v$. Esta tercera especie (Diosc.4.75) se tiene hoy por una de las numerosas variedades de Mandragora, afín posiblemente a la especie «macho» (Mandragora vernalis Bertol.). En el Renacimiento, no obstante, y sobre todo algunos botánicos alemanes -Bock, Cordus, Fuchs-, la identificaron con la belladona (Atropa belladona $\mathrm{L}$.) o alguna variedad de solano. 
tanto, de la mandrágora con la berenjena -ambas solanáceas- le lleva luego a Barbaro a añadir una breve descripción morfológica de esta última, tras referir que los antiguos no la habían conocido:

De morio mandragora nihil habeo quod addi possit iis quae a Dioscoride notantur, sed quoniam mala terrestria et canina mandragorae fructus appellantur, in mentem subeunt quae vulgo melenzana vocitamus, hoc est, ut ipse puto, mala insana, de quibus nihil veteribus scriptum fuisse iam desino mirari, quod multa huiusmodi reperio, sicut hercle multa quondam fuere, quae modo vel ignorantur vel certe non habentur. Mala ergo insana e frutice vulgari sunt, passim nascente, ut melones et cucurbitae, pari quoque cultu, foliis prope ficulneis, flore oblongo, specioso, candido. Manditur vulgo pomum ex oleo, sale, pipere, fungorum modo coctum (Barbaro 1516, f.79v).

Según Barbaro, pues, la berenjena era ya un fruto muy común en Italia, como los melones y las calabazas, de cultivo semejante ${ }^{15}$. Asimila sus hojas con las de la higuera y describe las flores como alargadas, hermosas y blanquecinas. Añade por último la forma habitual para su ingesta: se suele preparar como las setas, cocida con aceite, sal y pimienta. En todo caso, ni describe el fruto ni ofrece juicio sobre sus virtudes medicinales y sus posibles efectos dañinos, tan corrientes en las fuentes medievales.

Otro de los célebres traductores latinos de Dioscórides, el francés Jean Ruel (Rue1lius, 1474-1537), decano de la Facultad de Medicina de París, publicó en su último año de vida un De natura stirpium en que ofrece también su propio comentario de las berenjenas (Greene 1983, vol.2, pp.598-657; Valderas 1989). Construye su texto copiando sin más el testimonio de Barbaro, pero a su descripción añade ahora otros rasgos: se parece en las hojas y el tallo a la bardana mayor (Arctium lappa L.); el fruto es del tamaño de una manzana, redondeado, de color purpúreo o blanquecino, cuya pulpa, como la de las calabazas, es comestible. El fruto puede prepararse como señalaba Barbaro o también cocido en rodajas y aderezado luego con aceite o pimienta y vinagre. Los conserveros la disponen en salmuera para poder consumirla durante todo el año. Si en Italia decía Barbaro que era un fruto muy corriente y de consumo bastante popularizado, Ruel señala que en Francia se planta en huertos, pero sobre todo en macetas que se ponen en las ventanas como elemento decorativo, más que como planta de fruto comestible. Y concluye con una cuestión terminológica: acepta la expresión mala insana que Barbaro consideraba antecedente de la itálica «melanzana», pero señala que en Francia se la solía conocer popularmente por pomum amoris («pomme d'amour»), algo que solo se explicaría -continúa-por su apariencia elegante y hermosa, que la volvería digna de aprecio ${ }^{16}$.

\footnotetext{
${ }^{15}$ Las cucurbitáceas (melones, calabazas, sandías, pepinos, calabacines) y ciertas solanáceas (patatas, tomates, pimientos y berenjenas) son algunos de los vegetales más consumidos del mundo, de ahí que se les pusiera a menudo en relación, a pesar de ser de familias botánicas diferentes (Paris-Daunay-Janick 2009; Paris-Janick-Daunay 2011).

16 Pomum amoris habría de emplearse también para aludir al tomate. Asimismo, se consideró que ese nombre, más allá de la razón que se plantea Ruel, podría aludir a una supuesta virtud afrodisiaca de la berenjena (véase arriba, n.13). El texto completo es este: Nec sunt nunc praetereunda silentio melensana vulgo vocitata,
} 
También el ferrarense Antonio Musa Brassavola (1500-1554), discípulo de Niccolò Leoniceno (1428-1524) y Giovanni Manardo (1462-1536), y que publica su diálogo Examen omnium simplicium medicamentorum el mismo año que la obra de Ruel (Nutton 1997), señala también que la forma más habitual de encontrar las berenjenas en su tierra es in fictili supra fenestras, lo que abundaría en su uso como planta ornamental. En cualquier caso, Brassavola rechaza la propuesta de Barbaro: el morion de Dioscórides no es la berenjena, llamada también en la zona norte de Italia -y de nuevo con apelativo despectivo- «pomo desdegnoso»: ni enloquece como el morion ni, por tanto, es correcto que se la llame malum insanum, por lo que la conjetura terminológica de Barbaro y su misma argumentación serían nullius momenti. La planta de la berenjena, en efecto, no solo sirve de adorno, sino que su fruto se come a menudo en Nápoles y Venecia sin efectos adversos. Y añade datos de su propia experiencia: Isabel y Julia, dos nobles españolas hijas de Federico de Nápoles, que vivieron en Ferrara con su madre entre 1507 y 1533, solían comer comúnmente berenjenas, que cocían o freían con aceite, sal y pimienta o también con vinagre, y que dieron a probar no pocas veces al mismo Brassavola ${ }^{17}$. En cualquier caso, atribuye a Barbaro lo que en realidad no había dicho, pues ni proponía una identificación como tal entre ambas plantas, sino solo una asociación de nombres, ni consideraba que las berenjenas engendrasen locura o fuesen alucinógenas. Sin ofrecer, en fin, descripción alguna de la

quasi dicant mala insana, de quibus iam nihil veteribus fuisse scriptum desino mirari, quod multa huiusmodi reperio, sicut permulta quondam fuere, quae hodie vel ignorantur vel certe non habentur. Galli amorum poma nominant. Mala ergo insana e frutice vulgari dependent, qui personaceam frondibus et caule prorsus aemuletur. Is passim nascitur foliis prope ficulneis, flore oblongo, specioso, candido, fructu pomi magnitudine, in orbem absolutum circinato, colore vel puniceo vel niveo, in quibus cartilago gravis intercepta cucumeraceis continetur, quae edendo sit. Estur vulgo pomum ex oleo, sale, pipere, fungorum modo coctum. Alii ubi paulum inferbuit igni in orbiculos vel taleolas digerunt, et in acetariis ex oleo vel pipere et aceti momento mandunt. Salgamarii in muria acida servant, cibo per hyemem et ver ori non ingrato, sed tamen qui aegrius coquatur. Eodem gaudent cultu quo cucumeres et melones. In hortis apud nos seruntur, sed frequentius in fictilibus, ut fenestrarum pensiles hortulos exornent. Quur amoris pomum appelletur nostris haud scio, nisi forsitan quod elegans et perpulchrum placeat, et ita dignum quod ametur (Ruel 1537, p.584).

${ }^{17}$ In primis autem duo mandragorae genera ab autoribus poni scito, praesertim Dioscoride. Secundum genus morion dicitur. Hermolaus id pomum esse putat, quod vulgo desdegnoso nuncupamus, in fictili supra fenestras nascens. Argumentum habet, si quis ex hoc pomo comederit, insanus fit, ex hoc inquam quod morion dicitur. Nostra autem haec poma Ferrariae supra fenestras frequentia melanzana (a Neapolitanis praesertim, a quibus in summo honore habetur, et in magno usu est, et etiam Venetis) appellantur, quasi mala insana, haec autem potius coniectura est nullius momenti quam argumentum. Nam illustrissimas Isabellam et Iuliam Taraconenses per totam aestatem eiusmodi poma melanzana comedentes vidimus, et singulis annis, in pultariis decocta, et quandoque frixa ex oleo, sale, pipere et quandoque aceto, tamen nunquam insanae visae sunt, sed in dies sapientiores evasere. Nec ego ab illis abstinui, imo et ipsae illustrissimae sorores ad me cocta miserunt, quum Ferrariae habitarent (...) Sed his omissis, ad mandragoram veniamus: quippe secundam mandragorae speciem a Dioscoride positam melanzanum esse inficiamur vel (ut nos dicimus) desdegnosum pomum (Brasavola 1537, pp.311-312). Obsérvese que Brassavola llama al morion segunda especie de Dioscórides, pues entiende que la primera - y genuina - se dividiría en dos variedades, es decir, las llamadas «hembra» o negra y «macho» o blanca. No obstante, aluden al supuesto error de identificación los ya citados Paglia-Civitavecchia (1543, p.313): Brasaulus autem decipitur, asserens praefatum Hermolaum putasse melanzanum esse secundum genus mandragorae, scilicet masculinum, quoniam (ut patet legenti) Hermolaus de tertia specie hoc dixit, non de secunda. 
planta, Brassavola permite constatar una vez más el uso itálico de la berenjena como elemento decorativo y culinario.

Los naturalistas germanos de mediados del siglo XVI (Ogilvie 2006, pp.34-37 y 143-148) fueron los primeros que dieron una detallada descripción morfológica de la berenjena. Uno de los «padres alemanes» de la botánica, Heronymus Bock (Tragus, 1498-1554), aun recogiendo en cierta forma las noticas de Barbaro y Ruel, explica los rasgos de la planta con cuidado y precisión: los que llaman mala insana llegaron a Alemania desde Nápoles, aun cuando no se adaptaban con facilidad al clima germano, sobre todo en años lluviosos y fríos. Y narra su propia experiencia herbaria: le dio unas semillas el también botánico Georg Oellinger (1487-1557), semejantes a las de la pimienta india, pero de gusto no tan acre y de color rojizo; las plantó en una maceta, en la que nacieron primero una hojitas estrechas y puntiagudas, a las que siguieron otras más negruzcas, parecidas a las del solano silvestre (que viene a su vez a identificar con el morion dioscorídeo), pero más ásperas. Las ramas proceden de un único tallo de color purpúreo, que nace de una raíz pequeña y vellosa. Las flores, muy elegantes, pueden ser púrpuras o blancas, estrelladas, sujetas a pedúnculos ásperos, que a comienzos del otoño dan paso a unos frutos en forma de manzana de aspecto también muy elegante, llenos de semillas, unos de color púrpura y otros de color rojizo. La planta es muy bonita, pero de sabor poco agradable. Como las calabazas, no aguanta los fríos, por lo que debe plantarse cada año ${ }^{18}$.

La descripción de Bock, en cambio, contrasta con los datos que ofrece sobre el uso y virtudes de la planta, que siguen sin más la tradición: en latín -afirma- las berenjenas se llaman mala insana (la expresión se había extendido ya de forma generalizada), et iure quidem, cum ad sanitatem nihil faciant et difficulter concoquantur. Las describe como frías y húmedas (flemáticas, por tanto, frente a su tradicional concepción de coléricas y/o melancólicas) y malas para la salud, con efectos aparentemente semejantes a los de la mandrágora. Lo cual, por cierto, no quiere decir que sea la berenjena el morion de Dioscórides, pues también en este caso considera erróneo el juicio de Barbaro y propone su identificación con el que llama «solano silvestre», posiblemente la belladona. Reconoce, en fin, que las comen los italianos y los franceses, pero acon-

\footnotetext{
${ }^{18}$ Bock escribió su obra en alemán (Neu Kreutterbuch) y se publicó en Estrasburgo en 1539 sin ilustraciones. Los dibujos, a cargo de David Kendel, se añadieron para la edición de 1546. La obra se tradujo al latín (David Kyber) y se editó de nuevo con dibujos en Estrasburgo 1552 (Hoppe 1969; Greene 1983, vol.1, pp.304-359). De aquí citamos: Quae vulgo mala insana vocantur, ea e Neapoli in Germaniam commigrarunt, quanquam Germanis minus conveniant, ut quae non facile, praesertim annis pluviosis et frigidioribus, in nostris regionibus proveniant. Quod ad me attinet, primum omnium a domino Ollingero e Norimberga eorum semen, piperi Indico (de quo paulo post) fere consimile, sed non perinde acris gustus luteumque colore, accepi. Hoc in fictilibus primum plantare necesse fuit, in quibus angusta et acuta primo exortu eruperunt foliola, quae sequuntur alia nigricantia, forma sua solani sylvestri (quod mandragoram morion alias appellant) similia, sed tactu aliquantum asperiora. Singuli fructices unico rotundo contenti caule, qui e brevi et capillata prosilit radice, dimidium fere cubitum aequant. Inter purpureum hunc caulem et folia elegantissimi prodeunt flores, alii purpurei, alii albi, stellati, singuli asperis pediculis nitentes, qui autumno appetente in oblonga abeunt et aspectu elegantissima mala, granis referta, alia purpurea, alia lutea. Planta est speciosa aspectu, ut diximus, gustu vero et sapore non perinde grata. Est autem alsiosa frigorisque impatientissima, sicut et cucumeres, quare quotannis semine seri illam necesse est (Bock 1552, pp.894-895).
} 
seja, por si acaso, que se empleen solo como planta ornamental: Mihi enim animus non est pluribus illa verbis persequi, cui satis fuerit in hortis ea, cum elegantia solum et pulchritudine placere possint, inter caetera quae visum delectant, spectare (Bock 1552, p.895). Por lo demás, la ilustración que acompaña la edición latina (figura 2) presenta una planta bastante precisa, con flores y frutos a la vez, piriformes y no muy alargados.

El gran botánico alemán Valerius Cordus (Ritze, 15151544) compuso en torno a 1540 una Historia stirpium que su temprana muerte no le permitió editar, pero que Conrad Gessner (1516-1565) publicó póstuma en 1561 (Green 1983, vol.1, pp.368-418). La descripción botánica que allí se hace

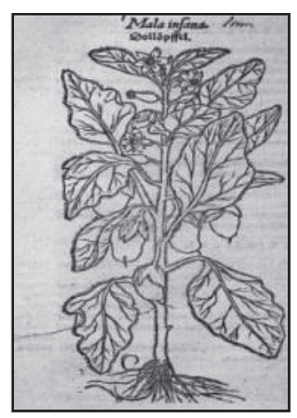

Figura 2. Bock 1552 , p. 894 de la berenjena es posiblemente la más completa de todo el Renacimiento, aun cuando reconoce que en Alemania solo se plantaba como elemento decorativo. Asimismo, alude ya a numerosas variedades según la forma y el color del fruto: alargado, ovalado, redondeado, recurvado hacia arriba, rojizo, amarillento, blanquecino. De sus cualidades nada afirma, salvo que no parece muy saludable y que solo los árabes la ingerían, sin conocer quizá la tradición culinaria de zona mediterránea. Pero a Cordus ya no le preocupaba tanto el valor farmacológico o dietético como la descripción botánica. Y, respecto al nombre, prefiere el tradicional melongena (así documentado, como sabemos, en la versión latina de Avicena) en vez del vulgar melanzana, que tiene por corrupto. Dice así el texto:

Melongena, quam Itali corrupto nomine melanzanam vocant. Prima qua seritur aestate caulem erigit longitudine cubitali, crassitudine minimi digiti, solidum lignosumque, in ramos inaequali ordine divisum, ex quibus alia prodeunt adnata. Folia iuxta alas fert dodrante breviora, quatuor digitorum latitudine, per ambitum parum et inaequaliter sinuosa, in mucronem desinentia, aspera et in confricando strepentia; secus ea longos rubentesque pediculos et in his singulos aculeatos calices, ex quibus singuli item nascuntur flores in quinque acuminata et rugosa foliola, stellae modo divisi, colore purpurascente, estque tota florum latitudo duorum fere digitorum, in quorum medio quinque sunt erecta lutei coloris stamina, in medio eorum uno eminente apice; florum foliola postquam defluxerint ex calicibus singuli subnascuntur fructus anatis et interdum anseris ovi magnitudine, nonnumquam oblongi et ovati, nonnumquam etiam rotundi et interdum sursum recurvi, colore plerumque rubente, quamvis etiam flavi et candicantes inveniantur, intus rara, lenta et fungosa carne constantes; apud nos sero maturescentes; in mediis fructibus sinuosae quaedam cavitates sunt, et in his semina copiosa, figura lentis, colore flavescente, minora tamen tenuioraque. Radicibus nititur numerosis in minimas fibras ceu capillamenta divisis. Seritur a nobis ad spectaculum in hortis aut fictilibus. Arabes etiam in alimentis fructu utuntur, sed vitiosum gignit succum. Saporem habet in dulci fatuum, pauca admixta amaritudine (Cordus 1561, ff.90v-91r) ${ }^{19}$.

\footnotetext{
${ }^{19}$ La ilustración de que Gessner hizo acompañar la descripción de Cordus fue la misma que se incluyó en la obra de Bock, por lo que no refleja exactamente todos los detalles y variedades que aquí se exponen.
} 
El otro gran «padre» de la botánica alemana, Leonhart Fuchs (1501-1566), publica en 1542 los De historia stirpium commentarii insignes. Pero, en este caso, el capítulo de la berenjena procede directamente de Jean Ruel, con algunos detalles tomados de Heronymus Bock. Señala, no obstante, la existencia de dos especies: una de frutos púrpuras y otra de frutos entre amarillentos y blanquecinos. Y respecto a su valor farmacológico se muestra tajante: nullum, quod sciam, in medicina usum habet (Fuchs 1542, p.532). Aun cuando se han valorado mucho las ilustraciones con que Fuchs adornó su herbario, la de la berenjena es muy semejante al tipo ya aparecido en la obra de Bock $^{20}$ (figura 3).

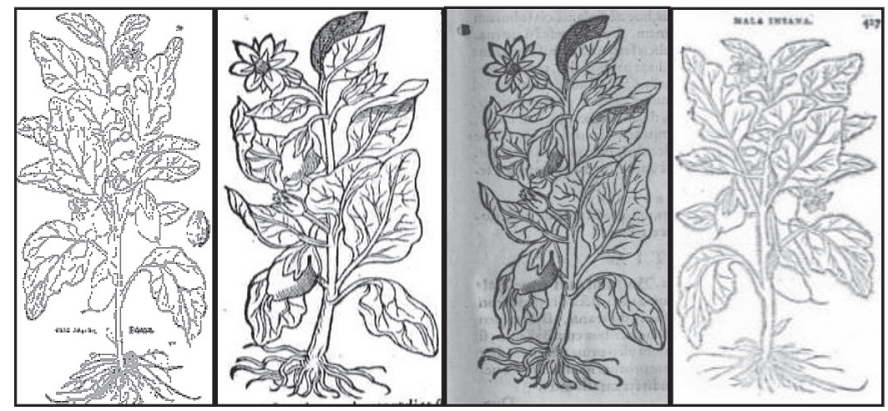

Figura 3. Fuchs 1542, f.532; Ryff 1549, p.321; Lonitzer 1551, f.75r; Dodoens 1553, p.427.

Dos franciscanos del convento de Santa Maria in Aracoeli de Roma, Angelo Paglia y Bartolomeo da Civitavecchia, editaron en 1543 un amplio comentario al llamado Antidotarium de Pseudo Mesué21. Al tratar de la mandrágora, vuelven ambos a desacreditar la asociación de Barbaro de la tercera especie dioscorídea y la berenjena, aun cuando reconocen que entre ambas plantas había sumo parecido. Y aducen dos razones principales para defender su postura: el morion es frío, mientas que la berenjena se decía que era cálida; el morion es soporífero y puede causar locura, mientras que la berenjena ni es lo uno ni hace lo otro. Y ponen ciertos ejemplos significativos para demostrarlo: un rústico comía berenjenas crudas con pan y sal y cada día estaba más sano y fuerte; e incluso ellos mismos las ingerían a menudo, ex coctis et cru-

\footnotetext{
${ }^{20}$ Hay edición facsímil de la obra de Fuchs, acompañada de un volumen introductorio: Meyer 1999. El texto de Fuchs se traduciría al alemán al año siguiente, con numerosas reediciones. Más adelante, Whalter $\mathrm{H}$. Ryff (1500-1548) copia el texto de Fuchs para sus comentarios a Dioscórides incluidos en la edición latina de Ruel de 1549 (Ryff 1549, p.329) (figura 3). Asimismo, el botánico Adam Lonitzer (1528-1586) reserva un capítulo para la berenjena en su Naturalis historiae opus novum, que en realidad es una suerte de 'refrito' de Fuchs y Bock, con una ilustración idéntica a la de Ryff, posiblemente hecha sobre la del propio Fuchs, aunque no idéntica (Lonitzer 1551, ff.75r-v) (figura 3). El dibujo de Fuchs, en cambio, se incluye exacto, aunque en posición inversa, en Dodoens (1553, p.427) (figura 3), quien de nuevo al año siguiente habría de reproducir dibujo y texto de Fuchs en su herbario flamenco Crüÿdeboeck (pp.297-298), traducido al francés por Charles de l'Ecluse (Clusius).

${ }^{21}$ Obra apócrifa compuesta en el norte de Italia en la segunda mitad del siglo XIII (Jacquart-Micheau 1990, pp.214-215; Lieberknecht 1995, pp.4-8).
} 
dis, et nunquam consequuti sumus ex ipsis aliquam apparentem laesionem in nostris membris. Y, en contraste con las opiniones habituales, terminan reivindicando las bondades alimenticias del fruto (sunt etenim optimi gustus cocta et edentibus magnam afferunt voluptatem), que corroboran con el ya comentado pasaje de Averroes (Paglia-Civitavecchia 1543, p.314) ${ }^{22}$.

El botánico y médico italiano Pietro Andrea Mattioli (1501-1577) publica en 1544 una traducción italiana de Dioscórides, acompañada de abundantes y eruditos comentarios (Ferri 1997; Sboarina 2000). En el capítulo de la mandrágora, como era de esperar, se ocupa de la identificación de la tercera especie con la berenjena y, aun cuando no está de acuerdo con ella, reivindica el testimonio de Barbaro (que ofrece íntegro en versión italiana) frente a dos de sus críticos (a los que había consultado, se supone, para tal cuestión): Musa Brassavola y Fuchs. Según Mattioli, Barbaro tan solo había establecido una asociación de ideas a partir de la semejanza de los nombres (poma canina / poma terrestria y mala insana), pero nunca había establecido su equivalencia o identificación. Y termina tras ello con unas breves alusiones a las cualidades de la berenjena, en especial -y así documentado por primera vez en un texto farmacológico- su condición afrodisíaca, que justifica por ser ventosa y de costosa digestión: «Usansi in Italia di mangiare questi frutti per provocare à lussuria. Il che fanno agevolmente, per essere et ventosi, et duri da digerire» (Mattioli 1550, p.601) ${ }^{23}$. Y termina con el testimonio negativo de Avicena, que contrasta con el más positivo de Averroes.

El texto de Mattioli sobre la berenjena permaneció idéntico en las siguientes ediciones italianas y latinas de la obra, hasta que lo amplió para la edición en latín de 1565 , en la que además se añadió una hermosa ilustración no muy diferente a la de los herbarios alemanes, con los frutos como siempre en forma de pera (figura 4). El añadido incluía una descripción botánica de la planta, que hasta entonces había obviado: aunque incluye en ella mínimas novedades (compara sus hojas, por ejemplo, con las del estramonio o el tamaño del fruto con el de una calabaza), el resto está tomado de la descripción de Cordus, que completa con las de Ruelle, Bock y Fuchs. Termina afirmando, como venía siendo habitual, que en Italia las berenjenas se comían a menudo y que solían prepararse sin piel, en rodajas, rebozadas con harina y fritas ${ }^{24}$.

\footnotetext{
${ }^{22}$ Los franciscanos escriben la obra en 1542, pero no la publican hasta el año siguiente. Aunque en la portada no aparece como tal, al comienzo del texto se pone por título Censura in Antidorarium Ioannis filii Mesue, que es como más se conoce el tratado desde las reediciones de Lión de 1546 y 1550.

${ }^{23}$ El valor afrodisiaco justificaría el nombre pomum amoris, que Ruel explicaba -como vimos- de otra manera: véase arriba, n.16. Por lo demás, el texto de Mattioli, tan influyente luego, es la base para las escasas noticias que de la planta se ofrecen en Amato Lusitano (1553, p.414).

${ }^{24}$ Caeterum nos mala insana e planta oriri observavimus, cui folia insunt stramoniae aut maioris solani haud absimilia, subaspera tamen, hirsuta et per ambitum sensim sinuata; caule unico, semicubitali, ramoso, tereti, firmo, subpurpureo et perinde ac folia hirsuto. Flores edit albicantes aut subpurpureos, in stellae modum radiantes, e quibus oblongi oriuntur fructus cucumeris magnitudine, colore in candido purpurescente, et laevissimo contecti cortice, succosa albicanteque intus pulpa, semine numeroso, parvo, siliquastri aemulo. Radice nititur multifida, haud alte descendente. Seritur in hortis et viridariis primo statim appetente vere. Floret aestate et autumno fert fructum. Planta est frigoris et algoris impatiens, quo fit ut in Germania et Boemia,
} 


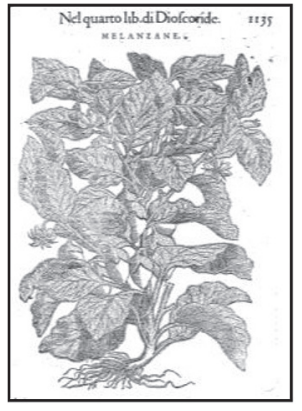

Figura 4. Mattioli 1565 , p.1078

El comentario a la mandrágora que Andrés Laguna (González Manjarrés 2000) incluye en su versión castellana de Dioscórides no hace tampoco destacadas aportaciones, pues viene a ser una copia más o menos retocada del texto italiano de Mattioli con algunos otros datos tomados de Fuchs. Al negar la identidad con el morion, para la que ni siquiera nombra ya a Barbaro, hace un resumen de la cuestión terminológica, aunque considera mala insana el nombre latino genuino (ignora melongiana, melongena o melongia) y piensa que poma amoris es una denominación medieval:

Creyeron algunos que las verengenas, llamadas mala insana de los latinos, y de los barbaros poma amoris, fuessen fructo de aquella tercera mandragora que llamo Dioscorides morion: en lo qual se engañaron, y la causa de aqueste error fue ver que morion en griego significa lo mesmo que en la lengua latina insanum, aunque cierto aquestos dos apellidos se dieron por respectos muy varios. Llamose la tercera suerte de mandragora morion porque priva del juyzio a los hombres y llamase insana a la verengena por quanto comida cruda es al gusto muy dessabrida (Laguna 1555, p.424).

Lo más interesante quizá sea el dato que ofrece sobre el consumo de la berenjena en España, siempre in malam partem: «En Castilla nace gran copia della, y en especial en Toledo, lo qual se les bolvio en vituperio y escarnio a los toledanos» (Laguna $1555, \mathrm{p} .425)^{25}$.

El médico, zoólogo y naturalista suizo Conrad Gessner (1516-1565) (FischerFüssli 1967; Bernhard Leu-Keller-Weidmann 2008), en la misma edición que hizo en 1561 de la Historia stirpium de Cordus, añadió una obrita titulada De hortis Germaniae, donde reserva un breve lugar para la berenjena y, más que nada, para ofrecer los muchos nombres con que ya se la conocía en diferentes lenguas: malum insanum, melongena, melantzana, $\mu \varepsilon \lambda \iota \zeta_{\zeta} \alpha \mathbf{v} \alpha$, strychnum, agriomelentzana. Gessner la considera con acierto una solanácea, de ahí que el nombre que él propone para ella sea solanum pomiferum. Termina el texto con la descripción de Ruel (Gessner 1561, f.266v).

Describe también con cierto detalle la berenjena el gran médico, filósofo y botánico italiano Andrea Cesalpino (1519-1603) en su influyente De plantis libri XVI de 1583 (Ogilvie 2006, pp.223-226), donde rechaza las tradicionales clasificaciones

ubi aestas frigidiuscula fuerit, raro fructum ad maturitatem perducat. In Italia, ubi mala insana copiosa proveniunt, frequenter in cibum veniunt. Elixa enim a cortice mundant et in particulas dissecant, et deinde farina aspersa in oleo aut butyro ferventi in patellis frigunt et mensis apponunt, sale et pipere condientes. Sunt enim gustui non ingrata (Mattioli 1565, p.1079). El añadido (texto e ilustración) se incorporaría luego a todas las ediciones de la obra, tanto latinas como italianas.

${ }^{25}$ La ilustración que trae la obra de Laguna es copia exacta de la de Ryff. El dato sobre las berenjenas toledanas lo repetirá años después el alemán Joachim Camerarius (1534-1598), en contraste con sus tierras alemanas, donde el fruto apenas podía madurar: apud nos fructus nunquam vidi maturos fieri (Camerarius 1588, pp.99-100). 
farmacológicas o alfabéticas de los vegetales. Llama al fruto pyrum insanum, de forma cónica, del tamaño de un melocotón, rojizo o purpúreo, aunque alude también a una variedad blanquecina, más agradable al gusto. En cualquier caso, se continúa aquí con su mala cualidad nutricia: aegre concoquitur in ventriculo (Cesalpino 1583, pp.210-211). Si bien no aporta demasiada novedad respecto a las descripciones de Bock o Cordus, Cesalpino identifica la planta -como habían hecho ya Bock, Mattioli o Gessner- con una solanácea y, más en concreto, con el «solano hortense» de Dioscórides (Diosc.4,71: Solanum nigrum L.), aunque más adelante, cuando habla del tomate, opta por el llamado «solano furioso», es decir, la belladona (preferida de Cordus y Fuchs para el morion y, al tiempo, para la mandrágora de Teofrasto [THPHR.HP6.2.9]).

En cualquier caso, los botánicos más importantes de la última parte del siglo XVI que tratan de la berenjena suelen recurrir a los mismos datos de toda la tradición precedente y que, en última instancia, remontan sobre todo a Barbaro, Ruelle, Bock y Cordus. Así ocurre, por ejemplo, en el Herbario novo del romano Castore Durante (1529-1590), un texto latino-italiano en que apenas se aporta nada nuevo al respecto y cuya ilustración sigue asimismo idéntica estela (Castore Durante 1585, p.266). Más interesa, dentro de su brevedad, el Appendix a la Historia Generalis Plantarum del botánico francés Jacques Delechamps (1513-1588), donde se distinguen dos grandes variedades de berenjena con apelaciones diferentes: melantzana Arabum, llamada de los árabes melongena o bedengia, y cuyo fruto puede ser de color ceniciento, amarillo o purpúreo, alargado y curvo como una calabaza; y melantzana nigra, que los Mauri vocant batleschain y cuyos frutos son alargados o redondos y de color negruzco (adjunta a esta segunda variedad la cita de Averroes) (Delechamps 1586, p.23). Presenta para ambas, además, sendos dibujos (figura 5), con el fruto alargado y más parecido al que hoy se consumen de forma mayoritaria en Occidente ${ }^{26}$.

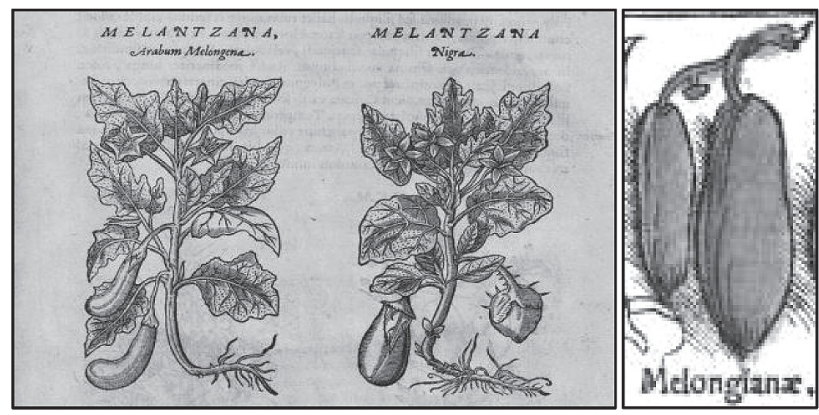

Figura 5. Delechamps 1586, p.23; Ibn Butlān 1531, p.56

El más importante botánico de finales del siglo XVI y comienzos del XVII fue el suizo Caspar Bauhin (1560-1624), con quien arranca ya la botánica moderna (Arber

\footnotetext{
${ }^{26}$ Como ya se hacía, por lo demás, en la breve ilustración de la berenjena (figura 5) que se incluyó en 1531 en la edición de la traducción latina del Tacuinum sanitatis (Butlān 1531, p.56) (véase arriba, n.13).
} 


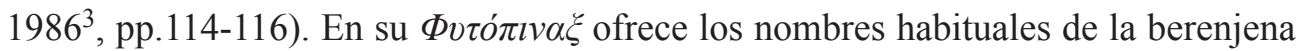
(prefiere llamarla, como Gessner, Solanum pomiferum), aduce la identificación de Cesalpino con el solano hortense de Dioscórides y, como Delechamps, distingue dos grandes variedades de acuerdo a la forma de su fruto: solanum pomiferum fructu oblongo (y de color variado: purpúreo, rojizo o blanquecino) y solanum pomiferum fructu incurvo (de color amarillento, ceniciento o purpúreo) (Bauhin 1596, p.300)27.

En definitiva, y de acuerdo a la propia evolución de la historia natural en el Renacimiento, la berenjena pasó de interesar como posible identificación para una planta discutida de Dioscórides a ser objeto de descripción en sí misma: por un lado, se fueron detallando cada vez más sus características morfológicas y puramente botánicas, emparentándola atinadamente con la familia de las solanáceas; pero por otro, y ya más en un plano farmacológico, la atribución de sus cualidades -cuando se hacía- siguió muy de cerca la estela árabe y medieval. En todo caso, desde el principio suele aludirse a la extensión de su consumo (en Italia, España y Francia sobre todo, mientras que en Alemania apenas llegaría a madurar y se cultivaba solo como planta de adorno) y a sus peculiaridades alimenticias y digestivas, en un amplio abanico de opiniones que irían de su desconsideración general a casos de directa recomendación.

\section{CONCLUSIONES}

Aun cuando la berenjena se cultivaba y consumía en Oriente desde tiempos remotos, la planta y su fruto no pasaron a formar parte de la materia médica antigua. Es posible que griegos y romanos llegasen a conocerla -al igual que ocurrió con otras plantas exóticas-, pero no le concedieron categoría culinaria ni farmacéutica, por lo que no se documenta en sus textos. Hay que esperar, en efecto, a la literatura árabe para que la berenjena haga acto de aparición libresca: su cultivo se estaba extendiendo y, por tanto, no solo se consumía como alimento, sino que empezó también a ser objeto de indagación medicinal, tanto por sus efectos adversos como por sus propiedades beneficiosas. Los árabes, por tanto, trajeron la planta a Occidente y posibilitaron con sus obras que también empezase a formar parte de la literatura farmacológica latina.

De hecho, las primeras documentaciones de la berenjena en latín se deben a versiones de tratados árabes (Isaac Israelí, Avicena, Averroes, Tacuinum sanitatis), en las que se recoge casi en exclusiva su valor farmacéutico, a menudo negativo. Desde un punto de vista cualitativo, se la suele tener por planta seca, casi siempre cálida (de ahí que genere humor colérico), pero a veces también fría (por ello puede inducir asimismo melancolía). En tal sentido, sus aportaciones suelen ser negativas: opilaciones, afecciones epidérmicas, hemorroides; pero no faltan recomendaciones medicinales

\footnotetext{
${ }^{27}$ Lo mismo viene a decir luego en sus Additiones a Dioscórides, incluidas en los Opera omnia de Mattioli que él mismo edita en Fráncfort 1598, p.761, aun cuando allí ofrece los diferentes nombres que suelen darse a la berenjena y los autores modernos más importantes que tratan de ella; y otro tanto, en fin, en el Pinax theatri botanici, Basilea 1623, p.167.
} 
para esos mismos daños, así como preparados especiales para su cómoda ingesta. Tal es, en definitiva, como poco a poco empieza a recogerse en algunos textos latinos medievales (Circa instans, Alphita, Matteo Silvatico, Tractatus de herbis), donde apenas se aporta nada nuevo ni se incluye descripción morfológica alguna, más allá de considerar sus frutos negruzcos y alargados.

Ya en el Renacimiento, la berenjena aparece con frecuencia en las dos modalidades más habituales de literatura farmacológica: los comentarios a Dioscórides y los herbarios propios. Desde que Ermolao Barbaro la relacionase, por pura asociación terminológica, con el morion de Dioscórides y diese luego de ella una breve descripción morfológica y culinaria, fueron numerosos los botánicos y naturalistas que la trataron a lo largo del siglo XVI. Desde el comienzo se insiste en dos aspectos fundamentales: la planta servía de adorno y sus frutos se consumían comúnmente -con diferentes preparados- en zona mediterránea. Pero si poco a poco la descripción se hizo más detallada y completa, sobre todo entre botánicos del norte de Europa (Bock, Cordus, Fuchs, etc.), que cultivaban las berenjenas ex professo por no darse allí para consumo, la consideración farmacológica seguía más bien la tradición libresca de origen árabe, casi siempre in malam partem: indigestas, engendradoras de malos humores y sin apenas utilidad medicinal. Con el tiempo, no obstante, los naturalistas privilegiaron la descripción botánica por encima de cualesquiera referencias farmacológicas, de forma que -según se ve al final, por ejemplo, en Bauhin- apenas interesan ya sus posibles usos médicos, sino solo su identificación y sus características.

Precisamente el afán de identificación exacta de la planta hizo que, siguiendo la huella de los «padres» alemanes de la botánica, los naturalistas de finales de siglo (Gessner, Cesalpino, Bauhin) la asimilasen correctamente con otras solanáceas y, más en concreto, con alguno de los diferentes solanos descritos ya en Dioscórides, como se podía leer también en ciertos códices de la tradición del Tractatus de herbis. No en vano, aunque Barbaro había vislumbrado, en el plano terminológico, cierta relación de la berenjena con el morion, se vio luego (Paglia y Civitavecchia, por ejemplo, o el italiano Mattioli) que morfológicamente la planta guardaba cierta relación con la mandrágora y, en definitiva, con otras solanáceas semejantes como la misma belladona, que a su vez sirvió para que algunos la identificasen con el morion de Dioscórides y la mandrágora de Teofrasto.

La berenjena, en definitiva, entró en Occidente de manos de los árabes y, en el ámbito literario, fue deudora de ellos -para bien y para mal- durante siglos. A medida que se extendieron su cultivo y su consumo, sobre todo en zona mediterránea, los botánicos y naturalistas fueron detallando su descripción morfológica (no pocas veces manifestada en dibujos cada vez más realistas, aun cuando quepa observar aquí también una tradición con escasas variaciones), al tiempo que descuidaban, por puro desinterés, sus posibles efectos medicinales. A lo sumo, como se ha visto, se comentaba su valor culinario y se ofrecían indicaciones marginales para consumirla en buenas condiciones. Pero más tocaba ya el asunto a gastronomía que a ciencia. 


\section{REFERENCIAS BIBLIOGRÁFICAS}

Amato Lusitano (1553), In Dioscoridis Anazarbei de medica materia libros quinque enarrationes, Venecia, G. Scoto.

Arber, A. $\left(1986^{3}\right)$, Herbals. Their Origin and Evolution. A Chapter in the History of Botany, 1470-1670, W.T. Stearn (ed.), Cambridge, Cambridge University Press (=1912).

ArVeILleR, R. (1969), «Les noms français de l'aubergine», Revue de Linguistique Romane $33,225-244$.

Averroes (1553), Colliget libri VII, Venecia, Giunta.

Avicena (1507), Liber canonis, Venecia, P. Paganini (= Hildesheim 2003).

Barbaro, E. (1516), Hermolai Barbari ... Corollarium, Venecia, Aloisio \& Francesco Barbaro.

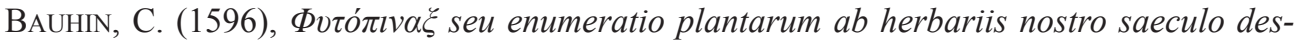
criptarum cum earum differentiis, Basilea, S. Henricpetrus.

BERG, R. et alii (eds.) (2001), Solanaceae V, Nijmegen, Nijmegen University Press.

Bernhard Leu, U. - Keller, R. - Weidmann, S. (2008), Conrad Gessner's Private Library, Leiden-Boston, Brill.

Bock, H. (1552), De stripium, maxime earum, quae in Germania nostra nascuntur ... commentariorum libri tres, Estrasburgo, W. Rihel.

BotTiglieri, C. (2007), «Appunti per un'edizione critica del Liber pandectarum medicinae di Matteo Silvatico», en JACQUART, D.-PARAVICINI BAgliani, A. (eds.), La Scuola medica salernitana. Gli autori e i testi, Florencia, Sismel-Edizioni del Galluzzo, pp.31-57.

BrassaVola, A.M. (1537), Examen omnium simplicium medicamentorum, quorum in officinis usus est, Lión, Jean \& François Frelloni.

Burnett, Ch. - Jacquart, D. (eds.) (1994), Constantine the African and 'Ali Ibn Al-'Abbās Al-Magūsī: The Pantegni and Related Texts, Leiden, Brill.

CAmerarius, J. (1588), Hortus medicus et philosophicus, Fráncfort del Meno, J. Feyerabend.

Castore Durante (1585), Herbario novo, Roma, G. Hertz.

Cesalpino, A. (1583), De plantis libri XVI, Florencia, G. Marescotto.

ClÉMEnT-Mullet, J.-J. (1864-1867), Le Livre de l'Agriculture d'Ibn al-Awam (Kitāb alFilāhah), 2 vols., París, A. Franck-A.L. Herold.

Cogliati Arano, L. (1976), The Medieval Health Handbook Tacuinum Sanitatis, Londres, Barrie \& Jenkins.

Collins, M. (2000), Medieval Herbals: The Illustrative Traditions, Londres, British LibraryUniversity of Toronto Press.

Cordus, V. (1561), Historia stirpium, C. Gessner (ed.), Estrasburgo, I. Rihel.

Corriente, F. (2008), Dictionary of Arabic and Allied Loandwords, Leiden-Boston, Brill.

DAS, S. et alii (2011), «Cardioprotective Properties of Raw and Cooked Eggplant (Solanum melongena L.)», Food \& Function 2.7, 395-399.

Daunay, M.C. (2008), «Eggplant», en Prohens, J. - Nuez, F. (eds.), Handbook of Plant Breeding. Vegetables II, Nueva York, Springer, pp.163-220.

Daunay, M.C. et alii (2001), "Genetic Resources of Eggplant (Solanum melongena L.) and Allied Species: A New Challenge for Molecular Geneticists and Eggplant Breeders», en BERG, R. et alii (eds.), Solanaceae V, Nijmegen, Nijmegen University Press, pp.251-274. 
DAUnAY, M.C. - JANICK, J. (2007), «History and Iconography of Eggplan», Chronica Horticulturae 47.3, 16-22.

DAUnAY, M.C. - JANick, J. - LATERROT, H. (2007), «Iconography of the Solanaceae from Antiquity to the 17th Century: A Rich Source of Information on Genetic Diversity and Uses», Acta Horticulturae 745, 59-88.

Delechamps, J. (1586), Historia generalis plantarum. Appendix, Lión, G. Roville.

Dodoens, R. (1553), Trium priorum de stirpium historia commentariorum imagines ad vivum expressae, Amberes, J. Loei.

Doganlar, S. et alii (2002), «A Comparative Genetic Linkage Map of Eggplant (Solanum melongena) and Its Implications for Genome Evolution in the Solanaceae», Genetics $161.4,1697-1711$.

Dubler, C.E. (1942), «Sobre la berenjena», Al-Andalus, 7.2, 367-390.

Elkhadem, H. (1990), Le Taqwim al Sihha (Tacuini Sanitatis) d'Ibn Butlan: un traité médical $d u$ XI siècle, Lovaina, Peeters.

Ferri, S. (ed.) (1997), Pietro Andrea Mattioli (Siena 1501-Trento 1578). La vita e le opere, Perugia, Quattroemme.

FISCHER, H.-Füssli, O. (eds.) (1967), Conrad Gessner, 1516-1565: Universalgelehrter, Naturforscher, Arzt, Zúrich, O. Füssli.

FuCHS, L. (1542), De historia stirpium commentarii insignes, Basilea, Isengrin.

García GonzÁlez, A. (2007), Alphita, Florencia, Sismel-Edizioni del Galluzzo.

Gessner, C. (1561), De hortis Germaniae, Estrasburgo, I. Rihel.

Givens, J.A. (2006), «Reading and Writing the Illustrated Tractatus de Herbis, 1280-1526», en Givens, J.A. - ReEds, K.M. - Touwaide, A. (eds.), Visualizing Medieval Medicine and Natural History, 1200-1550, Aldershot, Ashgate, pp.115-145.

GonzÁlez Manjarrés, M.Á. (2000), Andrés Laguna y el humanismo médico. Estudio filológico, Valladolid, Junta de Castilla y León.

GonzÁlez Manjarrés, M.Á. - Herrero Ingelmo, Ma⿳C. (2004), Un herbario ilustrado sin texto. El códice Vat. Chigi F. VII 158, Madrid, Testimonio-Biblioteca Apostólica Vaticana.

GReENE, E.L. (1983), Landmarks of Botanical History, F.N. Egerton (ed.), 2 vols., Stanford, Stanford University Press.

Hawkes, J.G. et alii (eds.) (1979), The Biology and the Taxonomy of the Solanaceae, Londres, Academic Press.

Hawkes, J.G. et alii (eds.) (1991), Solanaceae III: Taxonomy, Chemistry, Evolution, Londres, Royal Botanic Gardens.

Hoeniger, C., «The Illuminated Tacuinum Sanitatis Manuscripts from Northern Italy ca. 1380-1400: Sources, Patrons, and the Creation of a New Pictorial Genre», in GIVENS, J.A. - ReEds, K.M. - Touwaide, A. (eds.), Visualizing Medieval Medicine and Natural History, 1200-1550, Aldershot, Ashgate, pp.51-81.

HolleR, F.H. (1941), Das Arzneidrogenbuch in der Salernitanischen Handschrift der Breslauer Stadtbibliothek (Nr. 1302), Würzburg, K. Triltsch.

Hoppe, B. (1969), Das Kräuterbuch des Heronymus Bock, Stuttgart, Hierseman.

IBN Butlān (1531), Tacuini sanitatis ... de sex rebus non naturalibus, Estrasburgo, G. Scoto. IsAAC IsRaelí (1515), Omnia opera Ysaac, Lión, B. Trot-J. Platea. 
JACQuart, D. - Micheau, F. (1990), La médicine arabe et l'occident médiéval, París, Maisonneuve et Larose.

KHAN, R. (1979a), «Solanum melongena and Its Ancestral Forms», en HAwKES, J.G. et alii (eds.), The Biology and Taxonomy of the Solanaceae, Londres, Academic Press, pp.629636.

KHAN, R. (1979b), «Solanum melongena and the Problem of Its Origin and Phylogenetic Affinities», Journal of the Indian Botanical Society 58.2, 99-109.

Laguna, A., Pedacio Dioscorides Anazarbeo, Acerca de la materia medicinal y de los venenos mortiferos, Amberes, J. Laet.

Lester, R.N. - HASAN, S.M.Z. (1991), «Origin and Domestication of the Brinjal Eggplant, Solanum melongena, from $S$. incanum, in Africa and Asia», en HAWKES, J.G. et alii (eds.), Solanaceae III, Taxonomy, Chemistry, Evolution, Londres, Royal Botanic Gardens, pp.369-388.

Lev, E. - Amar, Z. (2008), Practical Materia Medica of the Medieval Eastern Mediterranea According to the Cairo Genizah, Leiden-Boston, Brill.

Lieberknecht, S. (1995), Die Canones des Pseudo-Mesue. Eine mittelalterliche PurgantienLehre, Stuttgart, Wissenschaftliche Verlagsgesellschaft.

LONITZER, A. (1551), Naturalis historiae opus novum, Fráncfort, Ch. Egenolf.

Löw, I. (1924-1934), Die Flora der Juden, 4 vols., Viena-Leipzig, Löwit.

Maíllo SAlgado, F. (1999³), Los arabismos del castellano en la baja Edad Media, Salamanca, Universidad de Salamanca.

Matteo Silvatico (1541), Pandectae medicinae, Lión, T. Payen.

Mattioli, P.A. (1550), Il Dioscoride dell'eccelente dottore medico P. Matthioli da Siena con le suoi discorsi, Venecia, Valgrisi.

Mattioli, P.A. (1565), Commentarii in sex libros Pedacii Dioscoridis Anazarbei De materia medica, Venecia, Valgrisi.

Mazliak, P. (2004), Avicenne et Averroès: medicine et biologie dans la civilization de l'Islam, París, Vuivert.

MeYer, E. (1867), Alberti Magni De vegetalibus libri VII, Berlín, G. Reimer.

Meyer, F.G. (1999), The Great Herbal of Leonhart Fuchs, Stanford, Stanford University Press.

MiLner, S.E. et alii (2011), «Bioactivities of Glycoalkaloids and Their Aglycones from Solanum Species», Journal of the Agricultura and Food Chemistry 59.8, 3454-3484.

NeE, M. et alii (eds.) (1999), Solanaceae IV. Advances in Biology and Utilization, Kew, Royal Botanic Gardens.

Nutton, V. (1997), «The Rise of Medical Humanism: Ferrara, 1464-1555», Renaissance Studies 11, 2-19.

OgiLvie, B.W. (2006), The Science of Describing: Natural History in Renaissance Europe, Chicago-Londres, University of Chicago Press.

Paglia, A. - Civitavecchia, B. (1543), In Antidotarium Ioannis filii Mesue, Venecia, B. de Zannetti.

PARIS, H.S. - DAunay, M.C - JANICK, J. (2009), «The Cucurbitaceae and Solanaceae Illustrated in Medieval Manuscripts Known as the Tacuinum Sanitatis», Annals of Botany 103.8, 1187-1205. 
PARIS, H.S. - JANick, J. - DAUnAY, M.C. (2011), «Medieval Herbal Iconography and Lexicography of Cucumis (Cucumber and Melon, Cucurbitaceae) in the Occident, 13001458», Annals of Botany 108.3, 471-484.

Resman, D.C. (2002), The Making of the Avicennan Tradition. The Transmission, Contents, and Structure of Ibn Sinnà's al-Mubāhatatāt (The Discussions), Leiden-Boston-Colonia, Brill.

Rosner, F.-Muntner, S. (1970), The Medical Aphorisms of Moses Maimonides, 2 vols., Nueva York, Yeshiva University Press.

Ruel, J. (1537), De natura stirpium libri tres, Basilea, Froben.

Ryff, W.H. (1549), Pedanii Dioscoridis Anazarbei de medicinali materia libri sex, Ioanne Ruellio Suessionensi interprete ... Additis etiam annotationibus sive scholis ... per Gualtherum Rivium, Fráncfort, Egenolf.

Sboarina, F. (2000), Il lessico medico nel 'Dioscoride' di Pietro Andrea Mattioli, Fráncfort, Peter Lang.

Segre Rutz, V. (2002), Historia plantarum, erbe, oro e medicina nei codici medievali, volume di commento, Modena, Panini.

Sękara, A. - Cebula, S. - Kunicki, E. (2007), «Cultivated Eggplants. Origin, Breeding Objectives and Genetic Resources, a Review», Folia Horticulturae 19.1, 97-114.

SwAN, C., «The Uses of Realism in Early Modern Illustrated Botany», en Givens, J.A. ReEds, K.M. - Touwaide, A. (eds.), Visualizing Medieval Medicine and Natural History, 1200-1550, Aldershot, Ashgate, pp.239-249.

VALDERAS, J.M. (1989), «La teoría botánica de Jean Ruel (Ruellius, 1474-1537)», Collectanea Botanica 17.2, 273-288.

Ventura, I. (2010), Ps. Bartolomeo Mini de Senis. Tractatus de herbis. Ms. Londres, British Library, Egerton 747, Florencia, Sismel-Edizioni del Galluzzo.

Wang, J.-X. et alii (2008), «Ancient Chinese Literature Reveals Pathways of Eggplant Domestication», Annals of Botany 102.6, 891-897.

Watson, A.M. (1983), Agricultural Innovation in the Early Islamic World. The Diffusion of Crops and Farming Techniques, 700-1100, Cambridge, Cambridge University Press (reimpr. 2008). 